\title{
Net primary productivity, upwelling and coastal currents in the Gulf of Ulloa, Baja California, México
}

\author{
E. González-Rodríguez ${ }^{1}$, A. Trasviña-Castro ${ }^{1}$, G. Gaxiola-Castro ${ }^{2}$, L. Zamudio ${ }^{3}$, and R. Cervantes-Duarte ${ }^{4}$ \\ ${ }^{1}$ Centro de Investigación Científica y de Educación Superior de Ensenada (CICESE), Unidad La Paz, Miraflores No. 334, \\ Fracc. Bella Vista, La Paz 23050 BCS México \\ ${ }^{2}$ CICESE, Biological Oceanography Department. Ensenada, BC, México \\ ${ }^{3}$ Center for Ocean and Atmospheric Prediction Studies. Florida State University, Tallahassee, FL 32306, USA \\ ${ }^{4}$ Centro Interdisciplinario de Ciencias Marinas (CICIMAR-IPN), Oceanology Department. La Paz, BCS, México
}

Correspondence to: E. González-Rodríguez (egonzale@ cicese.mx)

Received: 26 August 2011 - Published in Ocean Sci. Discuss.: 27 September 2011

Revised: 1 August 2012 - Accepted: 5 August 2012 - Published: 30 August 2012

\begin{abstract}
The Gulf of Ulloa, a highly productive area off the western coast of the Baja California Peninsula, is examined for five successive years (2003-2007) by using satellite data and seasonal net primary productivity (NPP) estimates obtained from a vertical generalised production model. The results identify that northwestern winds blow parallel to the coast throughout the year. However, highest NPP occurs from March to June. During this period, an equatorward coastal current transports water from neighbouring upwelling areas to the northern Gulf of Ulloa and in combination with local upwelling, which injects nutrients into the euphotic zone, produce the observed increase in NPP. The opposite situation occurs in late summer when a warm poleward current of tropical characteristics arrives and inhibits the productivity in the whole region and generates the yearly lowest NPP levels. Our findings reveal the importance of lateral advection in the modulation of the primary productivity in this subtropical upwelling region.
\end{abstract}

\section{Introduction}

The Gulf of Ulloa (Fig. 1) is in the shallow sea off the west coast of the Baja California Peninsula limited to the north by Punta Eugenia $\left(28^{\circ} \mathrm{N} 115^{\circ} 30^{\prime} \mathrm{W}\right)$ and to the south by Bahía Magdalena $\left(25^{\circ} \mathrm{N} 111^{\circ} 30^{\prime} \mathrm{W}\right)$. The shelf is about $20 \mathrm{~km}$ wide off Bahía Magdalena; it widens to about $100 \mathrm{~km}$ in the central part of the Gulf of Ulloa and it narrows and almost disappears in the north near Punta Eugenia. Histori- cally, the Gulf of Ulloa has been associated with high levels of biological productivity and for this reason it has been declared as biological activity centre by Lluch-Belda (1999).

The west coast of the Baja California Peninsula belongs to the oceanographic region of the California Current System (CCS) and the region of interest is on its southern boundary. The California Current (CC) meanders offshore and modifies coastal hydrographic properties (temperature, salinity, oxygen, nutrient contents) when it approaches the coast. Its surface expression is more intense in May and June when the CC forms the weak Cabo San Lucas front, a boundary between the subarctic and subtropical waters off the entrance to the Gulf of California. A thorough description of the CC can be found in the keynote papers of Hickey (1979) and Lynn and Simpson (1987). The whole CC region is characterized by the presence of meanders, eddies and a coastal transition zone (CTZ) between it and the coastal waters during upwelling season. This CTZ contains large filaments associated with flowing squirts or jets (Davis, 1985; Rienecker and Mooers, 1989; Thomson and Papadakis, 1987), and eddies that contribute to the offshore transport of properties (Brink and Cowles, 1991) such as heat, nutrients, oxygen, chlorophyll, and salinity (Roemmich, 1989; Bograd et al., 2001).

The bathymetry of the Gulf of Ulloa changes from a wide, gentle sloping seafloor, between 24.5 to $26.2^{\circ} \mathrm{N}$ (Fig. 1), to steeper gradients when approaching to Punta Eugenia (Zaytsev et al., 2003). The shelf of the western Baja California Peninsula is highly productive, especially the wind-driven upwelling regions (Lluch-Belda, 1999; Zaytsev et al., 2003). 


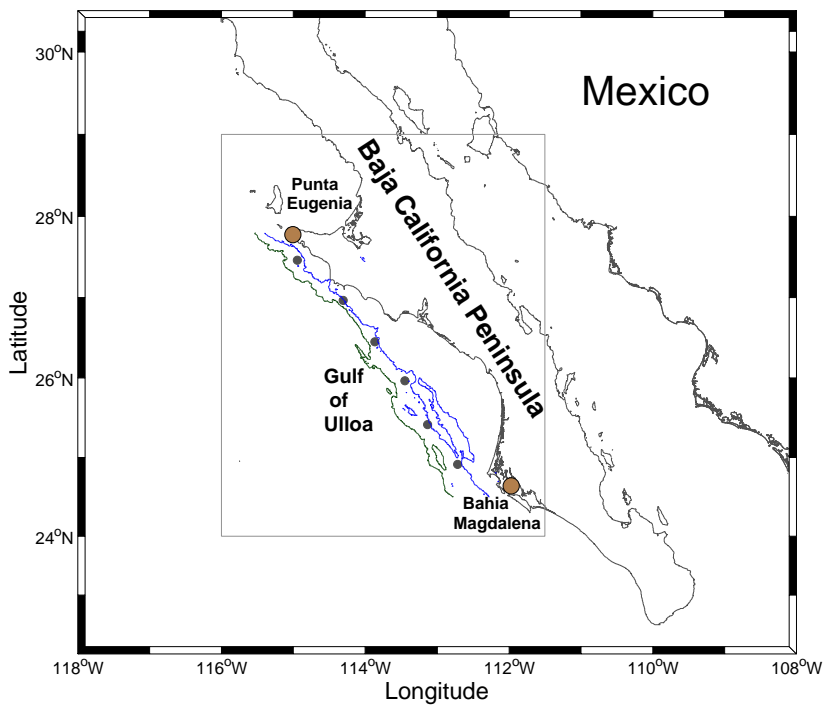

Fig. 1. The Gulf of Ulloa. The thin blue and green lines indicate the isobaths of $200 \mathrm{~m}$ and $1500 \mathrm{~m}$, respectively. The six grey filled circles on the limit on the continental shelf are the sample sites of the net primary productivity, currents and winds to generate mean time series for the region. The brown circles are the positions of Punta Eugenia and Bahía Magdalena, respectively. The rectangle shows the region that will be used in Figs. 2 to 5.

These upwelling events provide nutrient-rich water to the euphotic zone and support a productive ecosystem. Coastal upwelling occurs due to intense equatorward winds that blow on this coast throughout the year, creating the necessary wind stress and ensuing offshore Ekman transport (see for instance, Gill, 1982). In this paper the coastal zone is defined as the coastal region from the coastline until the coastal transition zone as defined in Chavez et al. (1991).

Upwelling regions are located along coast of the Baja California Peninsula (Nelson, 1977; Bakun and Nelson, 1977; Huyer, 1983). Specifically in the Gulf of Ulloa, from April to July, Lynn (1967) found the presence of narrow coastal cold water south of Punta Eugenia. The shape of the coastline is an important factor determining the location of upwelling centers as well as the generation of eddies and filaments (Haynes et al., 1993). Along the entire coast of the Baja California Peninsula the upwelling intensity changes in accordance with local wind conditions and bottom topography. Zaytsev et al. (2003) identified the seasonal and latitudinal variability of upwelling processes and found that the most permanent upwelling zones below $28^{\circ} \mathrm{N}$ are located at north and south of the Gulf of Ulloa, respectively.

In this paper we describe the effect of coastal upwelling on net primary productivity (NPP) off the west coast of Southern Baja California. We use satellite wind data and altimetryderived coastal currents to understand possible relationships between NPP, lateral advection and Ekman pumping.

\section{Methods}

In order to identify the seasonal variability of the wind patterns in the Gulf of Ulloa, monthly maps of wind and wind stress curl (WSC) were derived from daily averaged QUIKSCAT wind data (http://winds.jpl.nasa.gov/ missions/quikscat/index.cfm). According to Gill (1982), Ekman pumping is proportional to the WSC as follows:

$W_{\mathrm{E}}=\frac{1}{\rho f} \vec{\nabla} \times \vec{\tau}$

where

$W_{\mathrm{E}}$ is the Ekman pumping vertical velocity

$\rho$ is the water density (constant)

$f$ is the Coriolis parameter.

Consequently,

$\mathrm{WSC}=(\vec{\nabla} \times \vec{\tau})_{\hat{k}}=\left\{\frac{\partial \tau_{y}}{\partial x}-\frac{\partial \tau_{x}}{\partial y}\right\}$

where

$\tau_{x}$ and $\tau_{y}$ are the surface wind stress components.

The WSC is an "index" of upwelling intensity since the vertical ("pumping") velocity is proportional to it (Gill, 1982). Positive/negative WSC causes divergence/convergence in the Ekman layer and upward/downward Ekman pumping.

To characterize the seasonal behaviour of NPP in the Gulf of Ulloa we used monthly maps of NPP from a vertical generalised productivity model (VGPM) for the period from 2003 to 2007 between $24^{\circ}$ to $29^{\circ} \mathrm{N}$ and from $111^{\circ}$ to $116^{\circ} \mathrm{W}$ (see rectangle in Fig. 1). For the VGPM used in this study, the NPP is a function of chlorophyll $a$, available light, and the temperature-dependent photosynthetic efficiency, based on the following equation (Behrenfeld and Falkowski, 1997)

$\mathrm{NPP}=f_{\mathrm{PAR}} \cdot \mathrm{Chl} \cdot \mathrm{Pb} \cdot D_{\text {irr }} \cdot Z_{\mathrm{eu}}$

where

- NPP is the net primary productivity in $\mathrm{mg} \mathrm{C}^{-2} \mathrm{~d}^{-1}$.

- $f_{\mathrm{PAR}}$ is a function of the photosynthetically active radiation (PAR) in Einstein $\mathrm{m}^{-2} \mathrm{~d}^{-1}$. PAR data are obtained from SEAWIFS satellite.

- Chl is the satellite chlorophyll $a$ in $\mathrm{mg} \mathrm{m}^{-3}$, obtained from MODIS.

- $\mathrm{Pb}$ is also known as $\mathrm{Pb}_{\text {opt }}$ and it is the maximum rate of carbon fixation in the water column in $\mathrm{mg} \mathrm{Cmg} \mathrm{Chl}{ }^{-1} \mathrm{~h}^{-1} \cdot \mathrm{Pb}_{\text {opt }}$ was derived from satellite SST (MODIS) by fitting a polynomial to a large number of field $\mathrm{Pb}_{\text {opt }}$ values (Behrenfeld and Falkowski, 1997). 
- $D_{\text {irr }}$ is the daily light hours. A Matlab function to get the $D_{\text {irr }}$ was created according to http://www.science. oregonstate.edu/ocean.productivity/vgpm.model.php.

- $Z_{\text {eu }}$ is the euphotic zone depth in meters.

For this study, the euphotic zone depth in the VGPM was replaced by the mixed layer depth (MLD) obtained from results of the high resolution ocean general circulation model (HYCOM) (Bleck, 2002). We used MLD to implicitly include the dynamics of the coastal region as obtained from the HYCOM results. Integrating to the MLD also recognizes that satellite data do not resolve the vertical distribution of chlorophyll (for example, the deep chlorophyll maxima). Chlorophyll distribution is not vertically uniform across the euphotic zone, but it can be assumed to be uniform in layers as suggested by Platt and Sathyendranath (1993). Then, the vertical distribution of the phytoplankton over the water column can be divided in layers where each of them contains a uniform concentration. In these layers, the model can be applied to estimate the rate of net primary production. This is done in the MLD as a function of available light and phytoplankton chlorophyll (Platt et al., 1977; Platt and Gallegos, 1980; Cullen, 1990; Platt et al., 1990).

So the model was rewritten as follows:

$\mathrm{NPP}=f_{\mathrm{PAR}} \cdot \mathrm{Chl} \cdot \mathrm{Pb} \cdot D_{\text {irr }} \cdot \mathrm{MLD}$.

All variables, except $D_{\text {irr }}$ and MLD were obtained from satellite monthly data at $4 \times 4 \mathrm{~km}$ of resolution (Level 3, http: //oceancolor.gsfc.nasa.gov/cgi/l3). The daily $D_{\text {irr }}$ and MLD were recalculated to feed the monthly model time scale.

Monthly maps of satellite sea surface temperature (SST) were also generated with data from MODIS-AQUA level 3 at $4 \times 4 \mathrm{~km}$ of spatial resolution available from ocean colour home page (http://oceancolor.gsfc.nasa.gov) which is a dimensional array of the globe in an equidistant cylindrical projection stored in hierarchical data format (HDF) files. The algorithm chosen for SST was the one which uses the daytime $(11 \mu \mathrm{m})$ data. We use the daytime in order to have temperature simultaneous with chlorophyll used to obtain estimates of productivity. Additionally, Wan (2002) and Uiboupin and Sipelgas (2007) compared several algorithms and they reported the accuracy of the daytime algorithm as adequate.

Monthly maps of satellite geostrophic currents (currents hereafter) were estimated from altimetry data following the method described by Strub and James (2002). Sea level heights are obtained by adding the sea level anomaly from the satellite to the mean sea level long-term climatology from Levitus and Gelfeld (1992). The altimeter "msla" (map sea level anomalies) products are produced by Ssalto/Duacs and distributed by AVISO (http://www.aviso.oceanobs.com/en/data/products/ sea-surface-height-products/global/msla/index.html). The maps resolve the current field in a horizontal grid of a one-third degree.
Climatological monthly maps for the period (2003-2007) of all variables (winds, WSC, NPP, SST and currents) were generated (same zone of NPP, see rectangle in Fig. 1) by averaging the monthly maps previously created. To determine the seasonal behaviour of the NPP, currents and WSC, during the whole period (2003-2007) monthly time series, were generated at the six points marked in Fig. 1 (along the continental slope). In the case of the time series of currents, only the alongshore component $\left(V_{\mathrm{g}}^{*}\right)$ is considered. This results in rotating the reference frame to have alongshore and cross-shelf currents. Positive/negative values of the alongshore component indicate a poleward/equatorward current. We named this the geostrophic alongshore current (GAC).

A harmonic analysis of the NPP, GAC and WSC time series was carried out to obtain all the significant harmonics present in their respective time series. To find the dominant harmonics, the method of periodic regression (Bliss, 1958) was used. This method finds the trend and periodic components of a time series as defined by its frequency, amplitude and phase. The addition of several components can be used to describe most of the variability of the original time series (Bloomfield, 1976) and an F test was applied to evaluate the statistical significance of each harmonic. Once the main harmonics of the three time series (NPP, GAC and WSC) were found, cross-correlation tests were performed to get the time lag (in months) among the different time series. These describe the largest percentage of the variability of the original time series and are assumed to be the best choice to determine their interaction in seasonal scales.

\section{Results and discussion}

\subsection{Wind, WSC and SST: intra and interannual conditions}

Besides climatological monthly maps, yearly monthly maps during the period 2003-2007 for wind, WSC and SST were generated (not shown), but supplied as additional material. These results show that the wind direction blows parallel to the coast throughout the year, particularly near the coast, but it also has a seasonal behaviour with high wind speed from March to June, highest in April. Low winds speed were found from July to August. As a consequence, the coastal WSC was positive throughout the year. Cold SST occurs when the winds speed are high, primarily from March to June with the coldest water in north Gulf of Ulloa $\left(26-28^{\circ} \mathrm{N}\right)$ in April. The warm water was found from August to November. The interannual behaviour shows 2003 and 2007 as the years with the highest winds speed and coolest SST. Winds speed were weaker in 2004 and the warmer year was 2006. The WSC does not show a clear interannual variability. 


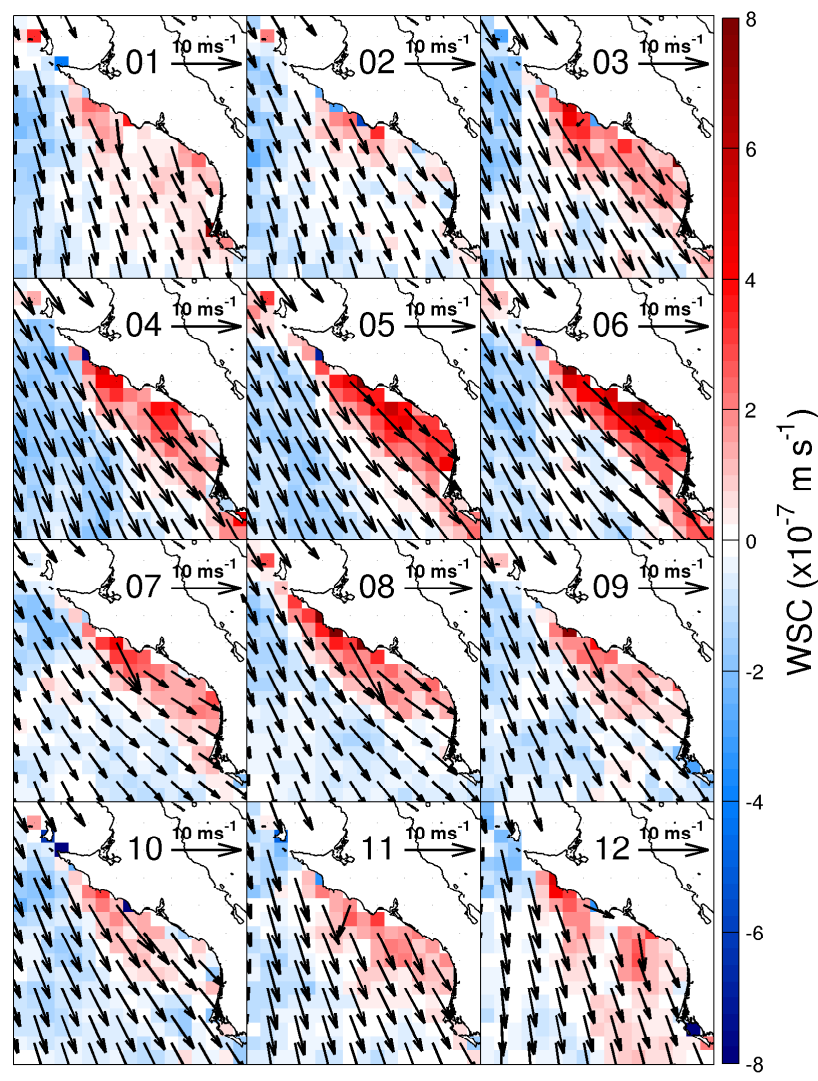

Fig. 2. Maps of monthly mean of wind features and wind stress curl (WSC) for 2003-2007. Numbers in each panel indicate the month of the year. For visualisation purposes, the vectors in each panel are plotted with half of their spatial resolution.

\subsection{Climatological maps of wind and wind stress curl (WSC)}

Wind vectors and WSC climatological monthly maps are shown in Fig. 2. Wind features are included only to show the regional monthly velocity patterns. The wind pattern off Baja California was pointed out by Bakun and Nelson (1977), who concluded that seasonal variability of wind speed is more important than direction (implying conditions are generally favourable for coastal upwelling throughout the year). With this wind pattern, the resultant WSC (Fig. 2) is positive onshore all year, except for small areas in February and October south of the Gulf of Ulloa. The months with the highest positive values of coastal WSC are March through June (values $>4.5 \times 10^{-7} \mathrm{~m} \mathrm{~s}^{-1}$ from 25 to $27^{\circ} \mathrm{N}$ ). Through July and August, coastal values of WSC range from 1.5 to $4 \times 10^{-7} \mathrm{~m} \mathrm{~s}^{-1}$. From September to January, values fall below $2 \times 10^{-7} \mathrm{~m} \mathrm{~s}^{-1}$. In the oceanic domain, the values of WSC were always negative.

From these maps an important question arises: if the wind (velocity) and the WSC patterns provide upwelling conditions throughout the year, why is the resultant NPP not con- sistently high? It is clear that in the Gulf of Ulloa wind favourable conditions are not the only force required for high NPP values. The presence of surface rich-nutrient water is inhibited in the summer by other processes. To provide support to this hypothesis, maps of climatological NPP, SST and currents (mean monthly values between 2003 and 2007) are discussed next.

\subsection{Climatological maps of NPP}

Climatological monthly maps of NPP are shown in Fig. 3. By January, maximum NPP values were below $600 \mathrm{mg} \mathrm{C} \mathrm{m}^{-2} \mathrm{~d}^{-1}$. The NPP values start to increase in February north to Gulf of Ulloa $\left(27^{\circ} \mathrm{N}\right)$ with values increasing to $1000 \mathrm{mg} \mathrm{C} \mathrm{m}^{-2} \mathrm{~d}^{-1}$. By March, NPP increases to $1500 \mathrm{mg} \mathrm{C} \mathrm{m}^{-2} \mathrm{~d}^{-1}$ in northern Gulf of Ulloa and highest values present all along the coast of Gulf of Ulloa, with values around $900 \mathrm{mg} \mathrm{C} \mathrm{m}^{-2}, \mathrm{~d}^{-1}$. In April, the coastal values increase to $1600 \mathrm{mg} \mathrm{C} \mathrm{m}^{-2} \mathrm{~d}^{-1}$. This month is the most productive of the year, in the five years considered. In May the NPP starts to diminish, with the coastal values in the range of 130 to $900 \mathrm{mg} \mathrm{C} \mathrm{m}^{-2} \mathrm{~d}^{-1}$. By June, the values in the coastal band are between 600 and $1250 \mathrm{mg} \mathrm{C} \mathrm{m}^{-2} \mathrm{~d}^{-1}$ but now only from the middle to northern Gulf of Ulloa $\left(26-28^{\circ} \mathrm{N}\right)$. In July and August only two small coastal regions can be observed with relatively high values of NPP, between 600 and $900 \mathrm{mg} \mathrm{C} \mathrm{m}^{-2} \mathrm{~d}^{-1}$. From September to December, the NPP values are very small in all the Gulf of Ulloa and all estimates are below $100 \mathrm{mg} \mathrm{C} \mathrm{m}^{-2} \mathrm{~d}^{-1}$. From the maps of Fig. 3 a seasonal behaviour in the NPP values is evident with maxima in spring and early summer (March to June) and minima from September to December, which is consistent with the upwelling season (see for instance Zaytsev et al., 2003).

In-situ primary production estimates by the Investigaciones Mexicanas de la Correinte de California (IMECOCAL) programme in few coastal stations (Martinez-Gaxiola et al., 2010) can be used to determine variability rates in organic carbon synthesis. Their measurements, however, cannot give NPP regional values for comparison with our estimates in Gulf of Ulloa. According to Kahru et al. (2009), chlorophyll $a$ drives most NPP responses along the coast of the California Current, and therefore the observed increase in phytoplankton biomass can be associated indirectly to the corresponding increase in NPP. The IMECOCAL data supports our findings (Fig. 3) regarding the spatial distribution of NPP. For instance, in the data of 2003 to 2007, the distribution of Chl in the Gulf of Ulloa shows similar coastal increases, with higher values south of Punta Eugenia in April associated with the upwelling process (data not shown). Similarly to the description of Fig. 3, a seasonal pattern occurs, associated with upwelling. Chl reached maximum values in April and decreased towards late summer (Goericke et al., 2004, 2005; Peterson et al., 2006; Goericke et al., 2007; McClatchie et al., 2008). 


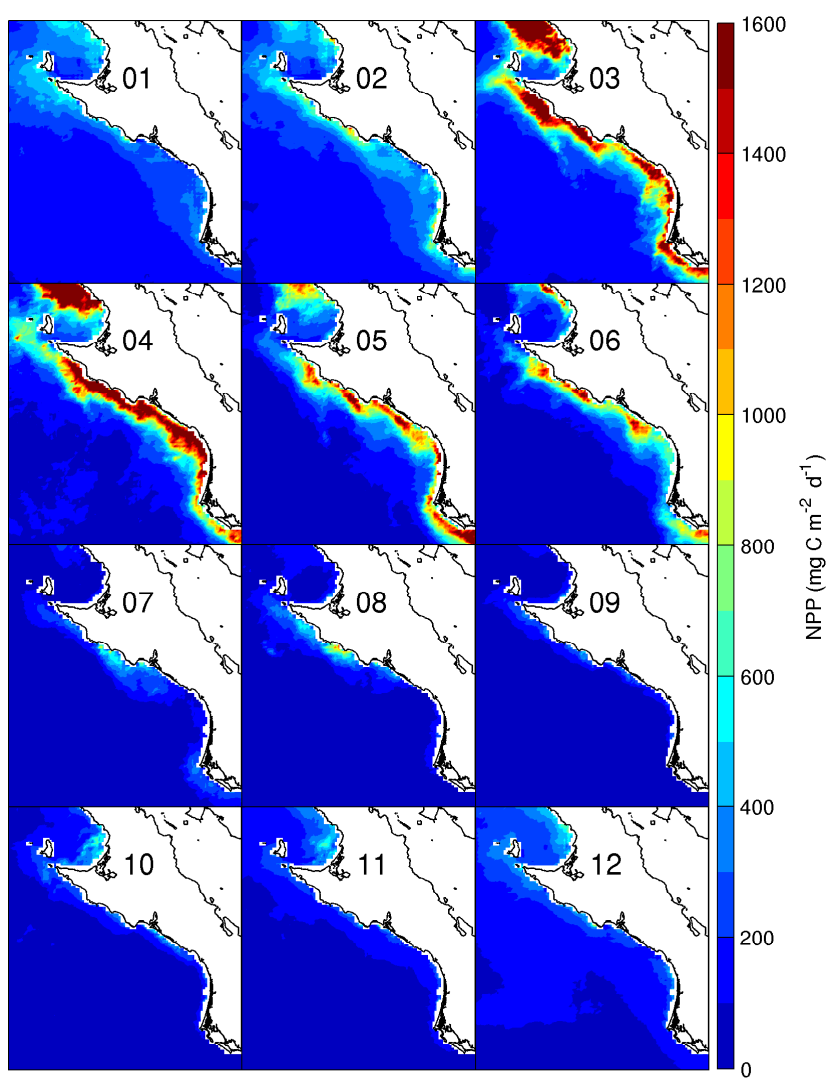

Fig. 3. Monthly climatology of NPP for 2003 to 2007. Numbers in each panel indicate the month of the year.

\subsection{Climatological maps of sea surface temperature (SST) and geostrophic currents}

\subsubsection{SST}

Monthly SST maps in Fig. 4 (current fields are superimposed) are shown. By January, SST has values from $14^{\circ} \mathrm{C}$ in the northern $\left(28^{\circ} \mathrm{N}\right)$ to $23^{\circ} \mathrm{C}$ in the southern $\left(25^{\circ} \mathrm{N}\right)$ Gulf of Ulloa. During February and March the lowest temperatures were north to $26^{\circ} \mathrm{N}\left(\sim 15^{\circ} \mathrm{C}\right)$, while in the southern region the maximum temperature observed was $21^{\circ} \mathrm{C}$. During April and May the coldest water $\left(\sim 12^{\circ} \mathrm{C}\right)$ is found again in the north but it now extends to middle Gulf of Ulloa $\left(26-28^{\circ} \mathrm{N}\right)$ and covers not only the coastal zone (the water over the continental shelf, indicated by the $200 \mathrm{~m}$ isobaths, Fig. 1) but the oceanic region. For these months during several years, the IMECOCAL programme reports a coastal band of cold water with high productivity near Punta Eugenia (Goericke et al., 2004, 2005; Peterson et al., 2006; Goericke et al., 2007; McClatchie et al., 2008). By June this behaviour is restricted to the northern coast (south of Punta Eugenia) with the lowest temperatures close to $15^{\circ} \mathrm{C}$. This appears to be the start of the relaxation of the upwelling season because water is less cold, and at the same time a mass of coastal warm water (temper- atures near to $21^{\circ} \mathrm{C}$ ) is present in the southern Gulf of Ulloa $\left(25-26^{\circ} \mathrm{N}\right)$. From July through August this warm water advances poleward to the middle Gulf of Ulloa $\left(26.5^{\circ} \mathrm{N}\right)$ not only along the coast but throughout the Gulf with temperatures of $26^{\circ} \mathrm{C}$ and higher, while coldest water $\left(18-19^{\circ} \mathrm{C}\right)$ is restricted to a narrow coastal band in the north $\left(27-28^{\circ} \mathrm{N}\right)$. By July, the core of the California Current is divided into two branches due to the presence of an eddy north of Punta Eugenia (Venrick et al., 2003; Goericke et al., 2004, 2005; Peterson et al., 2006; Goericke et al., 2007; McClatchie et al., 2008). The first branch is oceanic with warm temperatures; the second one is a narrow coastal equatorward jet of cold water associated with the remaining high values of $\mathrm{Chl}$ in the north coast. During September and October (Fig. 4), monthly maps show warmer water covering the central Gulf of Ulloa $\left(26-27^{\circ} \mathrm{N}\right)$ with temperatures of $28^{\circ} \mathrm{C}$. The minimum temperature of $20^{\circ} \mathrm{C}$ is found at about $27.5^{\circ} \mathrm{N}$ and there is no evidence of cold water associated with the upwelling. During the same months the IMECOCAL programme also reports the presence of warm water $\left(22-24{ }^{\circ} \mathrm{C}\right)$ and no evidence of the upwelling processes. By November, the water temperature begins to decrease in the northern Gulf of Ulloa, SST values are around $18^{\circ} \mathrm{C}$, while the southern end $\left(25^{\circ} \mathrm{N}\right) \mathrm{SST}$ remains near $25^{\circ} \mathrm{C}$. By December, the cooling water reaches $16^{\circ} \mathrm{C}$ in a small zone at northern Gulf of Ulloa $\left(28^{\circ} \mathrm{N}\right)$ and the higher values decrease to $23^{\circ} \mathrm{C}$ in the southern $\left(25^{\circ} \mathrm{N}\right)$. The maps of SST (Fig. 4) showed that favourable stronger upwelling conditions (the lowest coastal cold water) are present in April and are coincident with highest positive WSC (Fig. 2) and highest NPP values (Fig. 3) supported by corresponding high chlorophyll values in all the IMECOCAL reports previously mentioned.

\subsubsection{Geostrophic currents}

Monthly maps of Geostrophic Currents (currents) are shown in Fig. 4 (superimposed over SST). Monthly maps show that in January there is a weak coastal equatorward current in the northern Gulf of Ulloa. This current becomes stronger and wider from February to June, being strongest (maxima values $>0.20 \mathrm{~m} \mathrm{~s}^{-1}$ ) during April and May. During July and August, the equatorward current flows away from the coast creating oceanic meandering (curved) conditions, with no coastal current evident during these months. In September a warm poleward current enters the Gulf of Ulloa from the south, and by the month of November this current occupies the southern half of the Gulf of Ulloa. By December the same circulation persists, except that the surface temperatures start to decrease. When comparing the seasonal variations in the geostrophic currents as estimated here, with those reported by the IMECOCAL programme, results are very similar. The main features in the circulation patterns shown in Fig. 4 can also be found in the CALCOFI reports that include the IMECOCAL data (Venrick et al., 2003; Goericke 


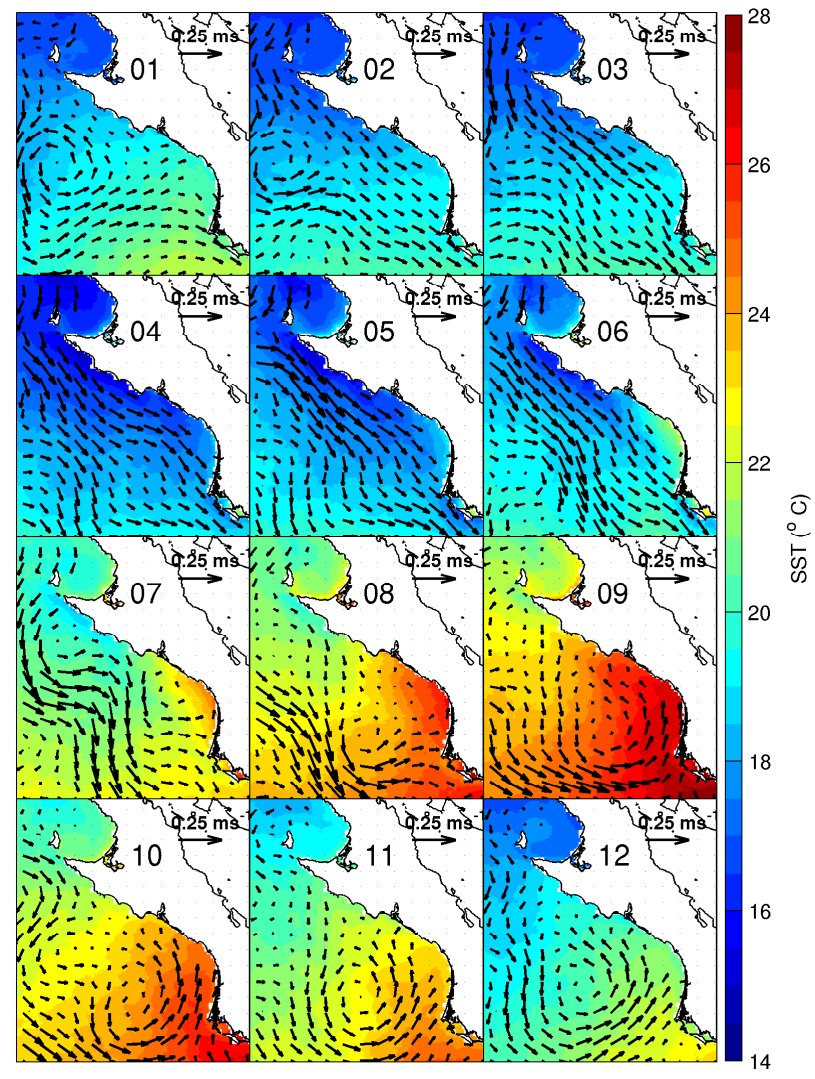

Fig. 4. Maps of monthly mean sea surface temperature (SST) and geostrophic currents for 2003-2007. Numbers in each panel indicate the month of the year.

et al., 2004, 2005; Peterson et al., 2006; Goericke et al., 2007; McClatchie et al., 2008).

When the currents are considered in conjunction with the other variables, the highest NPP values are a consequence of a positive WSC, lowest SST values, and strong equatorward flow. These oceanic conditions were found in Gulf of Ulloa from March to June with a maximum in April. When positive WSC values, relatively low SST values and weak equatorward flow are combined, the NPP values are not so high. Such conditions are found during January-February and July-August in the northern Gulf of Ulloa. Moreover, even with positive WSC values, when warm water provided by the poleward coastal flow is present, the NPP values are always low (September-December). This behaviour suggests that the local primary productivity results from local upwelling and also from the advection of the equatorward flow carrying cold nutrient-rich water. Roemmich (1989) and Bograd et al. (2001) describe the nutrient-rich California Current waters flowing south offshore. A similar process appears to occur in the shallow coastal region and it is partly responsible for the enhanced NPP.

To clarify this fact, maps of climatological currents are shown superimposed over NPP monthly maps (same period)
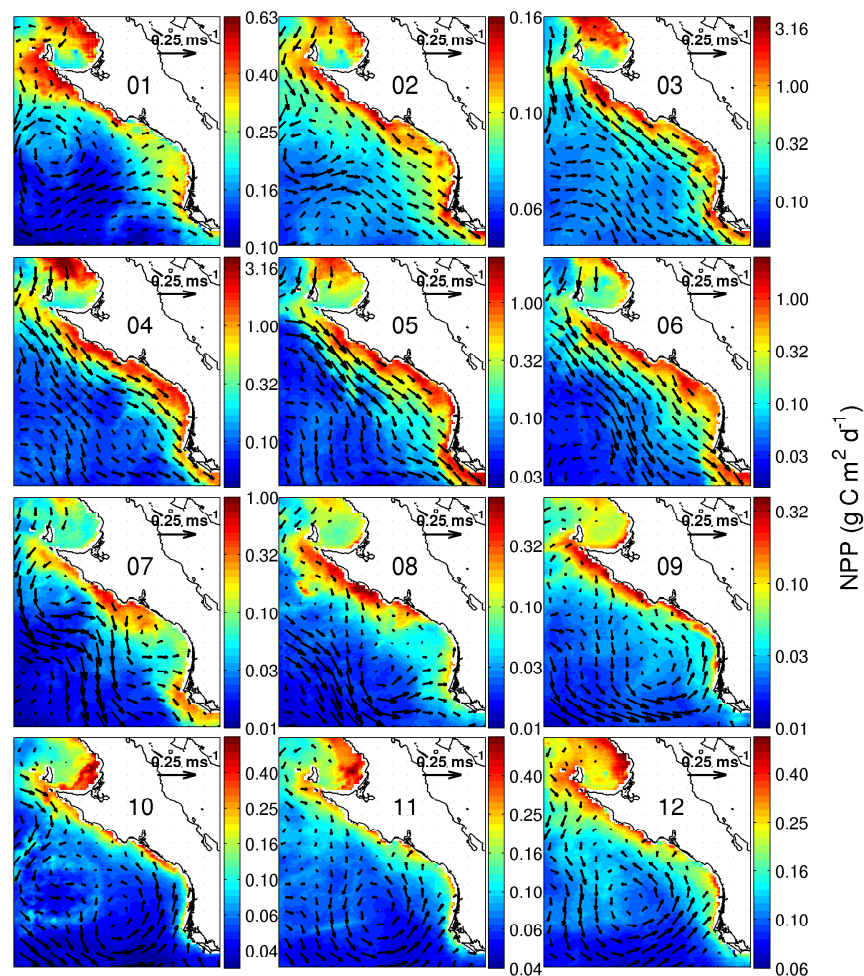

Fig. 5. Maps of monthly net primary productivity (NPP in logarithmic scale, different for each month) and geostrophic currents for 2003-2007. Numbers in each panel indicate the month of the year.

in Fig. 5. For a better display, the NPP (in colour) is presented in logarithmic (base 10) scale and each panel has its own scale. The circulation pattern from February to June shows a coastal equatorward current in the Gulf of Ulloa. The current is more intense from April to June and the presence of this equatorward current coincides with the increase of NPP coastal values from March through June. During July and August the equatorward current is located offshore; the lack of a coastal flow in these months and the presence of a warm poleward current during the rest of the year is associated with a sharp decrease in NPP values. Additionally, oceanic low NPP values are associated with the presence of an oceanic eddy more evident in October, but also present in December and January.

\subsection{Monthly time series}

The mean time series of monthly values from 2003 to 2007 of the six points in Fig. 1 for NPP, WSC and geostrophic alongshore component of the currents (GAC) are shown in Fig. 6. The NPP (green shaded curve) is present in both the upper (a) and middle panel (b) to compare its seasonal variability with the other variables. Maximum NPP values occur each year from spring to summer and are minimum in the autumn. The most productive year during the period of study is 2003 reaching $750 \mathrm{mg} \mathrm{C} \mathrm{m}^{-2} \mathrm{~d}^{-1}$ in spring. By the end of 


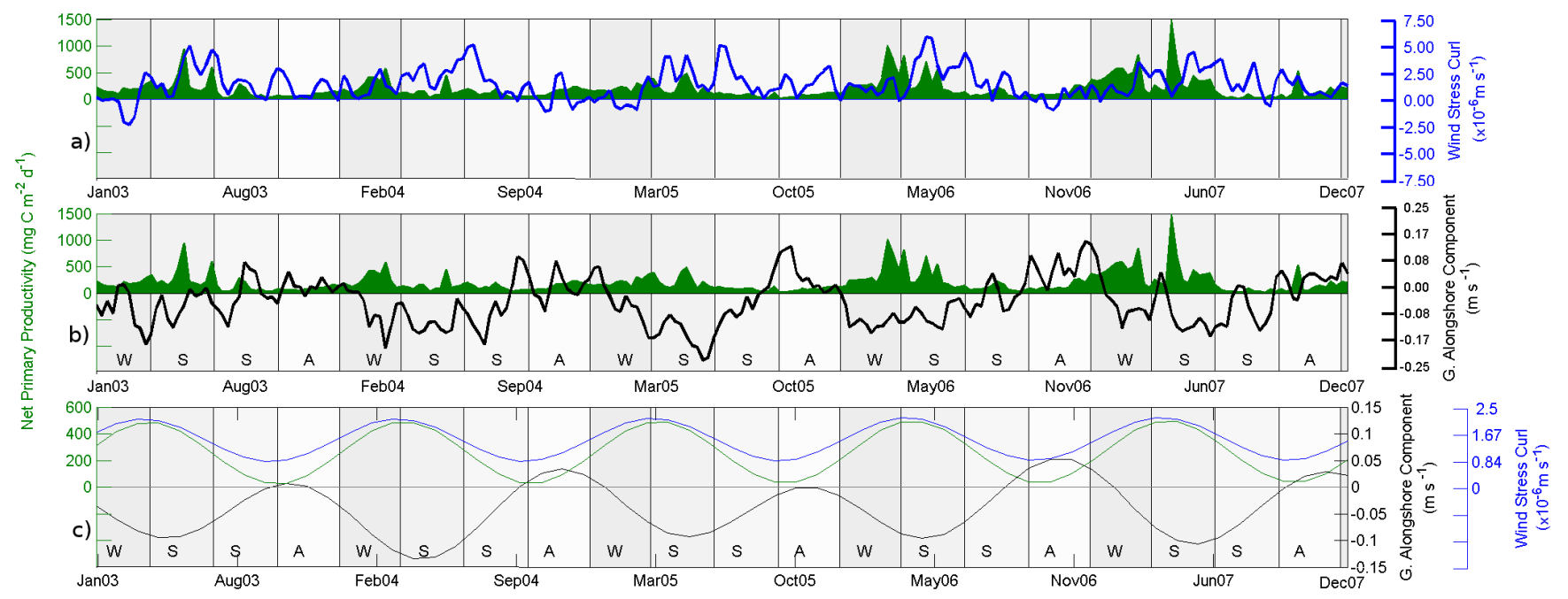

Fig. 6. (a) Time series of net primary productivity (NPP, green shaded) with wind stress curl (WSC, blue solid line) for 2003-2007. (b) Time series of NPP (green shaded) with geostrophic alongshore component (GAC, black solid line) for 2003-2007. (c) Dominant harmonics of the time series of NPP (green line), WSC (blue line) and GAC (black line). The vertical lines and the W, S, S and A letters indicate the seasons.

summer 2003, values decrease to less than $25 \mathrm{mg} \mathrm{C} \mathrm{m}^{-2} \mathrm{~d}^{-1}$. In 2004 the highest values of NPP are $450 \mathrm{mg} \mathrm{C} \mathrm{m}^{-2} \mathrm{~d}^{-1}$ in late spring and early summer. By 2005, the NPP starts to increase above $25 \mathrm{mg} \mathrm{C} \mathrm{m}^{-2} \mathrm{~d}^{-1}$ in winter. A secondary high of $400 \mathrm{mg} \mathrm{C} \mathrm{m}^{-2} \mathrm{~d}^{-1}$ is present in the early summer but the yearly maximum reaches $450 \mathrm{mg} \mathrm{C} \mathrm{m}^{-2} \mathrm{~d}^{-1}$ in the spring. In 2006, from mid-winter to mid-summer, the values of NPP lie above $250 \mathrm{mg} \mathrm{C} \mathrm{m}^{-2} \mathrm{~d}^{-1}$ with the highest value of $500 \mathrm{mg} \mathrm{C} \mathrm{m}^{-2} \mathrm{~d}^{-1}$ in early summer. By 2007 , the values of NPP are above $250 \mathrm{mg} \mathrm{C} \mathrm{m}^{-2} \mathrm{~d}^{-1}$ all winter and NPP remains high until late spring. In this year the NPP is the lowest in the summer for the whole period, but it is the highest in autumn for all five years. The NPP time series for the Gulf of Ulloa was dominated by the seasonal cycle.

In Fig. 6a, the WSC and NPP time series (upper panel) are compared. Positive WSC values occur practically during all five years, except for short periods in the winter 2003, autumn 2004, autumn 2007, and late summer 2007. The seasonal variability has two maxima for every year: the first one and with the highest values from $500-1000 \times 10^{-6} \mathrm{~m} \mathrm{~s}^{-1}$ in spring-summer in 2003, and a less intense period in the autumn with values from 250 to $500 \times 10^{-6} \mathrm{~m} \mathrm{~s}^{-1}$, with the only exception occurring in 2006 when values where slightly negative. In general terms NPP and WSC time series are well correlated: positive values of NPP occur with positive values of WSC. However, positive NPP occurs also when WSC values are negative, suggesting that the WSC is not the only process enhancing coastal productivity. Conversely, low values of NPP can occur even if positive WSC is present. In Fig. 6b (middle panel), we compare alongshore currents (GAC) with the NPP time series. GAC values are clearly seasonal. They show negative values (equatorward) from winter to late summer and positive values (poleward) from late summer to autumn. Both the equatorward (negative) and the poleward (positive) flow reach values of nearly $0.20 \mathrm{~m} \mathrm{~s}^{-1}$. Whenever the GAC flows equatorward, the NPP reaches high coastal values ( $>250 \mathrm{mg} \mathrm{C} \mathrm{m}^{-2} \mathrm{~d}^{-1}$ ). When GAC is close to zero or when it is positive (poleward current), the NPP begins to decrease with values below $150 \mathrm{mg} \mathrm{C} \mathrm{m}^{-2} \mathrm{~d}^{-1}$. The only exception was the summer of 2003. Even during the summer months with a weak poleward flow, NPP values remained high.

Therefore, the GACs are inversely related to NPPs. When GAC values reach a minimum, meaning that a strong equatorward current exists, the NPP reaches maximum values. Most of the positive GAC values are accompanied by low values of NPPs and this is consistent with the inhibition of the high productivity when poleward currents arrive carrying warm waters with tropical characteristics. We performed a harmonics analysis of the time series of NPP, GAC and WSC to obtain the dominant harmonic of each time series (Fig. 6c), as explained in the methods. Each harmonic explains $82 \%, 76 \%$ and $55 \%$ of the NPP, GAC and WSC variability, respectively. These components explain the seasonal behaviour and have 12 months periodicity. Only in the case of the WSC time series was a second cycle statistically significant, with the 6-month harmonics capable of explaining an additional $5 \%$ of the variability (not shown). In the case of NPP and WSC harmonics, the yearly maxima occurs almost simultaneously every April and May (cross-correlation coefficient of 0.99 at $0 \mathrm{lag}$ ) always preceded (by about one month) by the minima of the GAC indicating equatorward flow (cross-correlation coefficient of 0.97 at $-1 \mathrm{lag}$ ). 


\section{Conclusions}

Favourable upwelling wind conditions are present throughout the year in the Gulf of Ulloa, but high NPP exhibits clear seasonality. These upwelling winds, forcing Ekman suction by means of WSC, are necessary but not a sufficient condition for high coastal primary productivity. The highest levels of NPP are found from March through June, when a combination of positive WSC, lowest yearly SST values and equatorward currents carrying cold nutrient rich water occur throughout the coastal region. When the yearly equatorward current is the strongest (April-June), the NPP values are the highest of the year, and when this currents is weaker (January-February) or reversed (poleward flow in July-August) the corresponding NPP is inhibited. During July a transition occurs in the southern half of the California Current, as described in many CALCOFI reports. Off the Gulf of Ulloa, it splits into two branches near Punta Eugenia $\left(28^{\circ} \mathrm{N}\right)$, an oceanic branch that separates from the coast and a coastal branch that weakens towards the coast. At the same time warm waters of a poleward coastal flow arrive on the Gulf of Ulloa. Both factors contribute to the decrease of NPP observed in the satellite imagery and support data gathered by the IMECOCAL programme. The WSC time series show two extreme levels. The more intense one occurs during spring and summer and it is associated with the highest NPP levels of the year. The second period of high WSC occurs at the beginning of autumn, but NPP levels are the lowest of the year. In this case warmer and nutrient-deficient water carried by the poleward currents are thought to be responsible for the low NPP levels, despite the upwelling-favourable winds. The NPP rich waters of the Gulf of Ulloa are due to both the local upwelling and the equatorward coastal currents that carry nutrient rich waters from neighbouring upwelling areas from the north. Advection plays an important role in modulating the productivity of the western coast of Baja California at subtropical latitudes. The evidence presented over this fiveyear period is consistent with the seasonal modulation of the NPP of coastal upwelling and coastal currents.

\section{Supplementary material related to this article is available online at: http://www.ocean-sci.net/8/703/2012/ os-8-703-2012-supplement.pdf.}

Acknowledgements. Products from ESA's ERS-1 and ERS-2 data, CNES/NASA TOPEX/POSEIDON data and CLS 'SLA' were used. The altimeter products were produced by the CLS Space Oceanography Division as part of the Environment and Climate EU ENACT Project (EVK2-CT2001-00117) and with support from CNES. QUIKSCAT level 3 daily data is freely available at the web site of the Jet Propulsion Laboratory. MODIS level 3 data are freely available at the web site of OceanColor. HYCOM simulations were performed as part of the Office of Naval Research project Eddy Resolving Global Ocean Prediction Including Tides using challenge and non challenge time from the US Department of Defense (DOD) High Performance Computing Modernization Office on Cray XT5 and IBM P6 computers at the Navy DOD Supercomputing Resource Center, Stennis Space Center. Funding for this project came from the Consejo Nacional de Ciencia y Tecnología (CONACYT-México), project 32500-T. EGR, ATC and GGC are grant holders of the Sistema Nacional de Investigadores (CONACYT). Partial funding was also provided by the División of Oceanología of CICESE and by CICESE Unidad La Paz. English revisions by Fernanda Zamudio-Suarez. Final revisions by Jean R. Linero-Cueto.

Edited by: K. J. Heywood

\section{References}

Bakun, A. and Nelson, C. S.: Climatology of upwelling related processes off Baja California., CALCOFI Report, 19, 107-127, 1977.

Behrenfeld, M. J. and Falkowski, P. G.: Photosynthetic rates derived from satellite based chlorophyll concentration, Limnol. Oceanogr., 42, 1-20, 1997.

Bleck, R.: An oceanic general circulation model framed in hybrid isopycnic-cartesian coordinates, Ocean Model, 4, 55-88, doi:10.1016/S1463-5003(01)00012-9, 2002.

Bliss, C. I.: Periodic Regression in Biology and Climatology, New Haven, Connecticut Agricultural Experiment Station, Bulletin, p. 55, 1958.

Bloomfield, P.: Fourier Analysis of Time Series: An Introduction, Wiley Series in Probability and Mathematical Statistics, John Wiley \& Sons, 1st edn., 1976.

Bograd, S. J., Chereskin, T. K., and Roemmich, D.: Transport of mass, heat, salt, and nutrients in the southern California Current System: Annual cycle and interannual variability, J. Geophys. Res., 106, 9255-9275, doi:10.1029/1999JC000165, 2001.

Brink, K. H. and Cowles, T. J.: The Coastal Transition Zone Program, J. Geophys. Res., 96, 14637-14647, doi:10.1029/91JC01206, 1991.

Chavez, F. P., Barber, R. T., Kosro, P. M., Huyer, A., Ramp, S. R., Stanton, T. P., and Rojas de Mendiola, B.: Horizontal Transport and the Distribution of Nutrients in the Coastal Transition Zone off Northern California: Effects on Primary Production, Phytoplankton Biomass and Species Composition, J. Geophys. Res., 96, 14833-14848, doi:10.1029/91JC01163, 1991.

Cullen, J.: On models of growth and photosynthesis in phytoplankton, Deep Sea Res. Part A. Oceanographic Research Papers, 37, 667-683, doi:10.1016/0198-0149(90)90097-F, http://www. sciencedirect.com/science/article/pii/019801499090097F, 1990.

Davis, R. E.: Drifter observations of coastal surface currents during CODE: The method and descriptive view, J. Geophys. Res., 90, 4741-4755, 1985.

Gill, A. E.: Atmosphere-Ocean Dynamics, Academic Press, International, 1982.

Goericke, R., Bograd, S. J., Gaxiola-Castro, G., Gómez-Valdés, J., Hooff, R., Huyer, A., Hyrenbach, K. D., Lavaniegos, B. E., Mantyla, A., Peterson, W. T., Schwing, F. B., Smith, R. L., Sydeman, W. J., Venrick, E., and Wheeler., P. A.: The state of the 
California Current, 2003-2004: a rare "normal" year, CalCOFI Report, 45, 27-59, 2004.

Goericke, R., Venrick, E., Mantyla, A., Hoof, R., Collins, C., Gaxiola-Castro, G., Bograd, S. J., Schwing, F. B., Peterson, W. T., Marinovic, B., Durazo, R., Huyer, A., Smith, R. L., Wheller, P. A., Chavez, F., Lo, N. H. C., Hyrenbach, K. D., and Sideman, W. J.: The state of the California Current, 2004-2005: Still cool?, CALCOFI Report, 46, 32-71, 2005.

Goericke, R., Venrick, E., Koslow, T., Sydeman, W. J., Schwing, F. B., Bograd, S. J., Peterson, W. T., Emmett, R., Lara-Lara, J. R., Gaxiola-Castro, G., Gómez-Valdés, J., Hyrenbach, K. D., Bradley, R. W., Weise, M. J., Harvey, J. T., Collins, C., and Lo, N. C. H.: The State of the California Current, 2006-2007: Regional and Local Processes Dominate., CalCOFI Report, 48, $33-$ 66, 2007.

Haynes, R., Barton, E. D., and Pilling, I.: Development, Persistence, and Variability of Upwelling Filaments off the Atlantic Coast of the Iberian Peninsula, J. Geophys. Res., 98, 22681-22692, doi:10.1029/93JC02016, 1993.

Hickey, B. M.: The California current system-hypotheses and facts, Prog. Oceanogr., 8, 191-279, doi:10.1016/00796611(79)90002-8, http://www.sciencedirect.com/science/article/ B6V7B-48CFVK2-3/2/ed897f4bd8b15e53c4f9a363c37dbe23, 1979.

Huyer, A.: Coastal upwelling in the California current system, Prog. Oceanogr., 12, 259-284, doi:10.1016/00796611(83)90010-1, http://www.sciencedirect.com/science/article/ B6V7B-48BDPS0-N/2/a87e49c2bc3ded3bf8151bda442ea95a, 1983.

Kahru, M., Kudela, R., Manzano-Sarabia, M., and Mitchell, B. G.: Trends in primary production in the California Current detected with satellite data, J. Geophys. Res., 114, C02004, doi:10.1029/2008JC004979, 2009.

Levitus, S. and Gelfeld, R.: Key to Oceanography Records Documentation, No. 18., chap. NODC inventory of physical oceanography profiles., US Government Printing Office, Washington, D.C., 1992.

Lluch-Belda, D.: BAC's: Centros de Actividad Biológica del Pacífico Mexicano, chap. Centros de Actividad Biológica en la costa de Baja California, pp. 49-64, CIBNOR CONACyT, 1999.

Lynn, R. J.: Seasonal variation of temperature and salinity at 10 meters in the California current, CalCOFI Report, 11, 157-186, 1967.

Lynn, R. J. and Simpson, J. J.: The California Current System: The Seasonal Variability of its Physical Characteristics, J. Geophys. Res., 92, 12947-12966, doi:10.1029/JC092iC12p12947, 1987.

Martinez-Gaxiola, M., Durazo, R., and Gaxiola-Castro, G.: Influence of the geostrophic transport of phosphates on primary production off Baja California (Mexico), Ciencias Marinas, 36, 135-145, http://rcmarinas.ens.uabc.mx/index.php/cmarinas/ article/view/1660, 2010.

McClatchie, S., Goericke, R., Koslow, J. A., Schwing, F. B., Bograd, S. J., Charter, R., Watson, W., Lo, N., Hill, K., Gottschalk, J., L'Heureux, M., Xue, Y., Peterson, W. T., Emmett, R., Collins, C., Gaxiola-Castro, G., Durazo, R., Kahru, M., Mitchell, B. G., Hyrenbach, K. D., Sydeman, W. J., Bradley, R. W., Warzybok, P., and Bjorkstedt, E.: The state of the California Current, 20072008: La Niña conditions and their effects on the ecosystem, CalCOFI Report, 49, 39-76, 2008.
Nelson, C. S.: Wind stress and wind stress curl over the California current, Tech Report, NMFS-NOAA, pp. 1-87, 1977.

Peterson, W. T., Emmet, R., Goericke, R., Venrick, E., Mantyla, A. W., Bograd, S. J., Schwing, F. B., Hewitt, R., Lo, N. C. H., Watson, W. H., Barlow, J., Lowry, M., Ralston, S., Forney, K. A., Lavaniegos-Espejo, B. E., Sydeman, W. J., Hyrenbach, K. D., Bradley, R. W., Chávez, F. P., Warzybok, P., Hunter, K., Benson, S., Weise, M., Harvey, J., Gaxiola-Castro, G., and DurazoArvizu, R.: The state of the California current, 2005-2006: Warm in the north, cold in the south, CalCOFI Report, 47, 30-74, 2006.

Platt, T. and Gallegos, C. L.: In Primary productivity in the sea, chap. Modelling primary production of phytoplankton, pp. 339362, New York, Plenum Press, 1980.

Platt, T. and Sathyendranath, S.: Estimators of primary production for interpretation of remotely sensed data on ocean color, J. Geophys. Res., 98, 14561-14576, 1993.

Platt, T., Denman, K. L., and Jassby, A. D.: The Sea: Ideas and observations on progress in the study of the sea, chap. Modeling the productivity of phytoplankton, pp. 807-856, New York, John Wiley., 1977.

Platt, T., Sathyendranath, S., and Ravindran, P.: Primary Production by Phytoplankton: Analytic Solutions for Daily Rates per Unit Area of Water Surface, Proc. Roy. Soc. Biological Sci., 241, 101111, http://rspb.royalsocietypublishing.org/cgi/doi/10.1098/rspb. 1990.0072, 1990.

Rienecker, M. M. and Mooers, C. N. K.: Mesoscale eddies, jets, and fronts off Point Arena, July 1986, J. Geophys. Res., 94, 1255512569, 1989.

Roemmich, D.: Mean transport of mass, heat, salt and nutrients in southern California coastal waters: implications for primary production and nutrient cycling, Deep Sea Res. Part A. Oceanographic Research Papers, 36, 1359-1378, http://www. sciencedirect.com/science/article/pii/0198014989900885, 1989.

Strub, P. T. and James, C.: The 1997-1998 oceanic El Niño signal along the southeast and northeast Pacific boundaries - an altimetric view, Prog. Oceanogr., 54, 439-458, doi:10.1016/S00796611(02)00063-0, http://www.ingentaconnect.com/content/els/ 00796611/2002/00000054/00000001/art00063, 2002.

Thomson, R. E. and Papadakis, J. E.: Motion of satellite-tracked drifter along the west coast of North America,, J. Geophys. Res., 92, 6445-6461, 1987.

Uiboupin, R. and Sipelgas, L.: Comparison of satellite sea surface temperature with in situ surface layer temperature, Proc. Estonian Acad. Sci. Biol. Ecol., 56, 47-56, 2007.

Venrick, E., Bograd, S. J., Checkley, D., Durazo, R., GaxiolaCastro, G., Hunter, J., Huyer, A., Hyrenbach, K. D., Lavaniegos, B. E., Mantyla, A. W., Schwing, F. B., Smith, R. L., Sideman, W. J., and Wheeler, P. A.: The state of the California Current, 2002-2003: tropical and subarctic influences vie for dominance, CalCOFI Report, 44, 28-60, 2003.

Wan, Z.: Estimate of noise and systematic error in early thermal infrared data of the Moderate Resolution Imaging Spectroradiometer (MODIS), Remote Sensing. Enviroment, 80, 47-54, 2002.

Zaytsev, O., Cervantes-Duarte, R., Montante, O., and GallegosGarcia, A.: Coastal Upwelling Activity on the Pacific Shelf of the Baja California Peninsula, J. Oceanogr., 59, 489-502, doi:10.1023/A:1025544700632, 2003. 